\title{
Performed Observation Result Value Null Flavor Reason
}

National Cancer Institute

\section{Source}

National Cancer Institute. Performed Observation Result Value Null Flavor Reason. NCI

Thesaurus. Code C95371.

The explanation given as to why no performed observation result was provided. 